\title{
Estudos botânicos nos documentos educacionais: uma análise à luz da Etnobotânica
}

\section{Botanical studies in educational documents: an analysis in the light of Ethnobotany}

\author{
Francieli Luana Sganzerla (francisganzerla@gmail.com) \\ Programa de Pós Graduação em Educação em Ciências: Química da Vida e Saúde (PPGECQVS) \\ Universidade Federal do Pampa (UNIPAMPA)
}

Cadidja Coutinho (cadidjabio@gmail.com)

Professora Adjunta da Universidade Federal do Pampa e Docente do Programa de Pós Graduação em Ensino de Ciências.

Mara Regina Bonini Marzari (marabmarzari@gmail.com)

Professora Adjunta da Universidade Federal do Pampa e Docente do Programa de Pós Graduação em Educação em Ciências: Química da Vida e Saúde.

Resumo: Este estudo se pauta na investigação de documentos educacionais no âmbito das Ciências da Natureza $(\mathrm{CN})$ identificando e (re)conhecendo como o tema Etnobotânica está descrito e em quais perspectivas pedagógicas está pautado. O percurso metodológico deu-se através de uma abordagem qualitativa, com dados descritivos de uma análise documental do Referencial Curricular Gaúcho e Base Nacional Comum Curricular, referente ao currículo do Ensino Fundamental, no que tange o tema Etnobotânica nas CN. Utilizou-se a técnica de análise de conteúdo para identificação da expressão Etnobotânica, palavras correlacionadas ao termo nas habilidades dos documentos e estratégias pedagógicas, destacando-se as metodologias de alcance do conhecimento científico em Etnobotânica nos anos finais do Ensino Fundamental. Os dados mostram que os documentos estudados possuem abordagens e metodologias, ainda pouco expressivas, que possibilitam o ensino e a aprendizagem de Etnobotânica para alcançar o conhecimento científico através do saber popular. O estudo reconheceu os documentos oficiais, aproximando a Etnobotânica ao ensino de Ciências da Natureza, como também, demonstrando a necessidade e importância de refletir sobre o tema que ainda carece de estudos.

Palavras-chave: Educação científica; Análise Documental; Letramento Científico; Etnobotânica.

Abstract: This study is based on the investigation of educacional documents within the scope of the Sciences of Nature (CN) identified and knowing how the Ethnobotanical theme is described and in which pedagogical perspectives it is based. The methodological path took place through a qualitative approach, with descriptive data from a documentar analysis of the RCG (Gaucho Curriculum Reference) and BNCC (Common NationalCurriculum Base), referring to the curriculum of elementar education, with regard to the theme Ethnobotany in the $\mathrm{CN}$. The contente analysis technique was used to 
identify the expression. Ethnobotany, words correlated to theterm in the skills of documents and pedagogical strategies, highlighting the methodologies of reaching scientific knowledge in Ethnobotany in the final years of elementar school. The data show that the studied documents have na Ethnobotanical approach to reach scientific knowledge through popular knowledge. The study recognized the oficial documents, bringing Ethnobotany closer to the teaching of the Science of Nature, as well as demonstrating the need and importance of reflecting on the theme that still needs studies.

Keywords: Science Education; Document Analysis; Scientific Literacy; Ethnobotany.

\section{INTRODUÇÃO}

A Ciência pode ser considerada uma produção de cunho social e cultural? Partir dessa inquietação continua sendo uma reflexão pertinente na busca por explicações sobre os propósitos e os mecanismos para a elaboração do conhecimento científico. Pensar Ciência representa um empoderamento crítico e reflexivo para atribuir definições sobre a natureza do saber científico e para preparar os indivíduos à tomada de decisões, principalmente as que se referem ao seu cotidiano (CHASSOT, 2011a). De certo modo, caracteriza-se a Ciência como uma tarefa humana determinada de forma social e histórica, e por vezes de difícil entendimento para a maioria da população escolarizada (DELIZOICOV; ANGOTTI; PERNAMBUCO, 2011; COUTINHO, 2017).

Nesta perspectiva, a legislação educacional em suas atualizações parece estar se preocupando com a efetivação da educação científica, e no estado do Rio Grande do Sul, por exemplo, o documento norteador intitulado Referencial Curricular Gaúcho (RCG) já estabelece que "a Ciência tem como objetivo que o estudante consiga compreender e interpretar o mundo, bem como transformá-lo, tendo consciência de suas ações e consequências, as quais podem interferir no ambiente em que vive tornando a sociedade mais sustentável" (BRASIL, 2018c, p. 49). A elaboração do RCG teve como suporte teórico a Base Nacional Comum Curricular (BNCC).

[...] contendo seis cadernos pedagógicos divididos em Educação Infantil, Linguagens, Matemática, Ciências da Natureza, Ciências Humanas e Ensino Religioso. Cada caderno apresenta fundamentos pedagógicos, caracterização de suas áreas, componentes curriculares e o quadro organizacional do currículo contendo as unidades temáticas, objetivo do conhecimento, competências e 
habilidades da BNCC juntamente com habilidades do Estado do Rio Grande do Sul" (BRASIL, 2018c, p. 17).

No contexto brasileiro, a BNCC é um documento de caráter normativo de nível nacional, organizado em currículos e propostas adequados às diferentes modalidades de ensino (Educação Especial, Educação de Jovens e Adultos, Educação do Campo, Educação Escolar Indígena, Educação Escolar Quilombola, Educação a Distância), e que define o conjunto orgânico e progressivo de aprendizagens essenciais que todos os alunos devem desenvolver ao longo das etapas e modalidades da Educação Básica (BRASIL, 2018a).

Assim, relacionado a área de Ciências da Natureza, os documentos trazem uma concepção do conhecimento voltado à realidade local, social e individual do aluno, que é motivado a exercitar a observação, a experimentação e a investigação. Uma Ciência que possibilita instigar os estudantes a questionar e a divulgar seus conhecimentos, utilizandose de tecnologias existentes que proporcionam a contextualização para o desenvolvimento do pensamento crítico e criativo (BRASIL, 2018c).

Por outro lado, o ensino das Ciências da Natureza muitas vezes ainda está pautado na memorização de denominações e de conceitos, além da reprodução de regras, fugindo de um aprendizado de forma natural como deveria acontecer (BRASIL, 2006b). Além de descaracterizar a Ciência, esta forma de ensino acaba fazendo com que os alunos não compreendam as relações mais amplas que existem entre o que se estuda na sala de aula com os fatos que acontecem no dia a dia (RUPPENTHAL, 2013).

O desafio de pôr o saber científico ao alcance dos estudantes pode ser atingido pelos estudos etnobiológicos. Estes por sua vez, potencializam a associação entre os conhecimentos locais e globais, conectando culturas tradicionais e pesquisas científicas. Agregam relações biológicas e sociais da experiência humana no ambiente, como também, podem preencher lacunas no campo acadêmico por meio de conhecimentos das comunidades locais e suas relações com o ambiente (ARAÚJO; ALBUQUERQUE, 2009; LIMA et al., 2019). 
Assim sendo, o ensino de Ciências da Natureza pode estabelecer interfaces com a Etnobiologia, em especial com a Etnobotânica, possibilitando um novo olhar para os conceitos, aprimorando o conhecimento e o vínculo com as experiências que envolvem o meio ambiente, o desenvolvimento humano e as transformações tecnológicas (FERREIRA, 2018).

A Etnobotânica tem como foco o estudo das espécies da flora, preocupando-se em "entender a inter-relação direta entre pessoas de culturas viventes e as plantas de seu meio, aliando tanto fatores culturais quanto ambientais para entender as concepções dessas culturas sobre as plantas e o aproveitamento dado a elas" (LIMA et al., 2019, p. 2). Baseado nestes pressupostos, como a Etnobotânica está descrita nos documentos educacionais (RCG e BNCC) - Ciências da Natureza? Quais as possibilidades pedagógicas indicadas pelos documentos para o tema?

O presente projeto visa reconhecer a aproximação entre a Etnobotânica e educação científica, através de uma análise documental do RCG e da BNCC no âmbito das Ciências da Natureza.

\subsection{ETNOBOTÂNICA: EDUCAÇÃO CIENTÍFICA E SABER POPULAR}

O ensino de Ciências da Natureza está em constante movimento e vem mostrando sua importância para o desenvolvimento da educação científica, para a superação da premissa de acumulação de termos e conceitos, e para o estabelecimento de um saber preocupado com o envolvimento entre os estudantes e o conhecimento (SASSERON; DUSCHL, 2016).

Um ensino que aos poucos vem sendo aprimorado pela construção epistemológica dos saberes, quebrando paradigmas e metodologias tradicionais, desenvolvendo o conhecimento científico e populares, trazendo o aluno como sujeito da sua aprendizagem, ou seja, apresentando a Ciência como uma produção social e cultural.

Sasseron e Carvalho (2011) apresentam a concepção de ensino de Ciências como um processo de "enculturação científica" dos alunos, no qual são promovidas condições favoráveis para inserir os alunos à cultura científica. Essa por sua vez pode ser entendida 
como "Letramento Científico" se considerarmos o ensino de Ciências da Natureza como o conjunto de práticas às quais uma pessoa lança mão para interagir com seu mundo e os conhecimentos dele. Uma compreensão de conceitos científicos que permite a aplicação não apenas no contexto escolar, mas em todas as situações sociais que requisitem a Ciência (DIAS et al., 2019).

Para Leite et al. (2019, s/p) o "Letramento Científico é a capacidade de empregar o conhecimento científico para resolver questões, produzir novos conhecimentos, explicar fenômenos científicos e traçar conclusões baseadas em evidências em um contexto social". Desta forma, o Letramento Científico e o ensino de Ciências da Natureza podem estar interligados pela relação estabelecida entre o conhecimento científico e o saber popular, em uma aproximação aos estudos etnobiológicos, neste trabalho a Etnobotânica, proporcionando aos alunos novas formas de aprendizado e de construção da imagem da Ciência.

O resgate e a valorização de saberes populares trazidos para as salas de aula, mostrase um caminho que complementa a necessidade do Ensino de Ciências da Natureza, através do diálogo entre os saberes escolares e populares como mediadores do conhecimento científico, compreendido como facilitador da leitura do mundo natural (CHASSOT, 2008b).

As Ciências da Natureza vêm evoluindo durante décadas, construindo novos campos de conhecimento. Em destaque temos a Etnobiologia que é considerada como um campo do conhecimento de caráter transdisciplinar na qual os saberes da Biologia dialogam com conhecimentos de diferentes áreas (FERREIRA et al., 2017), aproximando os conhecimentos formais dos tradicionais, tomando-se referência da sua própria cultura (GUARIM, 2000).

No campo vasto da "Etnobiologia", que aos poucos vem conquistando seu espaço, os ramos do ensino de Botânica se divide em várias linhas de conhecimento, sendo uma delas a Etnobotânica, conhecida como a Ciência que estuda as inter-relações entre seres humanos e recursos vegetais ao longo do tempo (ALBUQUERQUE et al., 2010). Tais estudos são fundamentais para o desenvolvimento sustentável, permitindo aproveitar os 
recursos naturais a partir dos conhecimentos científicos e tecnológicos que as plantas podem oferecer (FONSECA-KRUEL; PEIXOTO, 2004).

Albuquerque (2005) menciona que a Etnobotânica está situada na fronteira entre a Botânica e a Antropologia cultural, por analisar a interação do natural (botânica) com o simbólico (costumes, ritos, crenças, entre outros). A Etnobotânica trata-se de um ramo da Ciência relativamente nova, que não tem sido sistematizada e formalizada como as outras Ciências já estabelecidas. Porém, já é reconhecida por muitos cientistas que valorizam e identificam seu relevante papel no desenvolvimento dos povos (HAMILTON et al., 2003).

Para isso, os conhecimentos tradicionais dos alunos precisam ser considerados e valorizados em todos os componentes curriculares trabalhados na escola, entre eles a disciplina de Ciências/Biologia, através da investigação e contextualização dos conhecimentos de diferentes culturas, acerca da biodiversidade local e dos demais elementos naturais encontrados em seu meio (SILVA; RAMOS, 2019)

Muitas intervenções humanas na diversidade florísticas ocorrem desde os primórdios da civilização. O ser humano busca na natureza recursos para melhorar suas condições de vida. A interação entre o homem e as plantas é fortemente evidenciada, uma vez que os recursos vegetais são utilizados de diversas maneiras, como é o caso da alimentação e das finalidades medicinais (GIRALDI; HANAZAKI, 2010). O resgate do conhecimento tradicional aliado à Ciência estimula a conservação dos recursos vegetais e o desenvolvimento sustentável de uma comunidade (KRUEL; SILVA; PINHEIRO, 2005).

Da mesma forma, a diversidade de grupos étnicos oportunizou o uso de plantas na forma integral em sua alimentação com base no saber popular, proporcionando subsídios para um maior conhecimento da flora local e regional (BRIÃO et al., 2016).

$\mathrm{Na}$ atualidade, a Etnobotânica constitui uma ponte entre o saber popular e o científico estimulando o resgate do conhecimento tradicional, a conservação dos recursos vegetais e o desenvolvimento sustentável, especialmente nos países tropicais e 
subtropicais, onde as populações rurais dependem em parte das plantas e seus produtos para sua subsistência (HAMILTON et al., 2003), bem como, o modo em que essas plantas são usadas como recursos (ROCHA et al., 2015).

Entretanto, percebe-se que no contexto escolar, o ensino de Botânica geralmente torna-se exaustivo por conter termos científicos baseado num ensino transmissivo e pautado no conhecimento morfológico e da nomenclatura vegetal. Isso favorece o desinteresse dos alunos e a desmotivação do professor, ocasionando um baixo índice de aprendizagem e tornando-se uma questão preocupante (BATISTA; ARAÚJO, 2015). O estudo das plantas requer disponibilidade e variedade de recursos didáticos, formação e atualização docente e a aproximação entre as crenças, as culturas, os saberes populares e a Ciência na sala de aula. Diante disso, a Etnobotânica pode representar um caminho promissor.

\section{METODOLOGIA}

A proposta de estudo previu uma análise documental do RCG e da BNCC no âmbito das Ciências da Natureza no que tange o tema Etnobotânica. A metodologia da pesquisa refere-se a uma abordagem qualitativa, utilizando dados descritivos dos documentos oficiais, ou seja, num processo de "garimpagem". A partir da leitura documental foram extraídas categorias de análises, pensadas e detalhadas a partir do objetivo principal do estudo.

A coleta de dados ocorreu pela identificação e descrição da utilização do termo Etnobotânica e/ou expressões correlacionadas nos documentos; detalhamento das perspectivas pedagógicas para abordagem do tema; verificação do(s) anos(s)/série(s) indicado(s) para abordagem da Etnobotânica.

Conforme afirma Bica (2013), acredita-se que o objetivo primário da perspectiva da análise documental seja representar para recuperar. Assim, sintetizou-se e representouse os resultados através da utilização de quadros descritivos e identificados abaixo (Quadros 1, 2 e 3), possibilitando ao leitor identificar a síntese das informações analisadas. 
No quadro 1 busca-se a identificação da utilização da expressão Etnobotânica no RCG e na BNCC, contendo a página de localização, o trecho da aplicação, o que o termo sugere para o ensino de Ciências da Natureza e em qual contexto é encontrado.

Quadro 1 - Utilização da expressão Etnobotânica no RCG e na BNCC.

\begin{tabular}{|c|l|l|c|c|}
\hline $\begin{array}{c}\text { Utilização } \\
\text { da expressão }\end{array}$ & $\begin{array}{c}\text { Página/local } \\
\text { ização }\end{array}$ & $\begin{array}{c}\text { Trecho da } \\
\text { aparição }\end{array}$ & $\begin{array}{c}\text { O que o termo } \\
\text { sugere para o } \\
\text { ensino de Ciências } \\
\text { a no texto Natureza }\end{array}$ & $\begin{array}{c}\text { Contexto } \\
\text { (introdução, } \\
\text { objetivos, etc.) }\end{array}$ \\
\cline { 2 - 5 } & & & & \\
\cline { 2 - 5 } & & & \multicolumn{2}{|c|}{} \\
\hline
\end{tabular}

Fonte: Adaptado de Soruco et al. (2019); Leite et al. (2019).

No quadro 2 analisa-se a utilização de palavras correlacionadas a Etnobotânica, identificando quais são e sua localização nos documentos, como por exemplo: botânica, plantas, ervas finas, ervas aromáticas, plantas medicinais, medicina tradicional, conservação ambiental, conhecimento popular, entre outras. Ainda, o trecho de aparição e o contexto (introdução, objetivos, habilidades, ano/série).

Quadro 2 - Utilização de palavras correlacionadas a Etnobotânica (quais/quantas/qual contexto).

\begin{tabular}{|c|c|c|c|}
\hline $\begin{array}{c}\text { Qual } \\
\text { palavra? }\end{array}$ & $\begin{array}{c}\text { Trecho (frase ou } \\
\text { parágrafo) }\end{array}$ & Contexto & Documento/Página \\
\hline & & & \\
\hline & & & \\
\hline
\end{tabular}

Fonte: Adaptado de Soruco et al. (2019); Leite et al. (2019).

No quadro 3 identifica-se as estratégias pedagógicas relacionadas ao tema Etnobotânica nos documentos, analisando as perspectivas indicadas, trecho sugerido para abordagem do tema, e contexto de aplicação (professores, alunos, escola, etc.)

Quadro 3 - Perspectivas de estratégias metodológicas relacionadas a Etnobotânica no documento (Sugere o que? Para trabalhar o que e/ou quando e para quem?).

\begin{tabular}{|c|c|c|c|}
\hline $\begin{array}{c}\text { Sugestão de } \\
\text { estratégias/metodolog } \\
\text { ias para alcançar o } \\
\text { conhecimento }\end{array}$ & $\begin{array}{c}\text { Descrição da } \\
\text { sugestão/trecho do } \\
\text { texto }\end{array}$ & $\begin{array}{c}\text { Voltado a que } \\
\text { público? } \\
\text { (Professor/aluno } \\
\text { /escola) }\end{array}$ & $\begin{array}{c}\text { Documento/ } \\
\text { Página }\end{array}$ \\
\hline
\end{tabular}




\begin{tabular}{|c|l|l|l|}
\hline $\begin{array}{c}\text { científico em } \\
\text { Etnobotânica? } \\
\text { Página? }\end{array}$ & & & \\
\hline & & & \\
\hline & & & \\
\hline
\end{tabular}

Fonte: Adaptado de Soruco et al. (2019); Leite et al. (2019).

Para a pesquisa, utilizou-se a técnica de Análise de Conteúdo proposta por Bardin (2011), com procedimentos sistemáticos e determinados objetivos para a descrição do conteúdo das mensagens e também de estatística descritiva. Ou seja, organização e sistematização das ideias, exploração do material e tratamento dos resultados obtidos desenvolvendo agrupamentos em função de características comuns.

\section{RESULTADOS E DISCUSSÃO}

A partir da análise documental, não foi encontrada a expressão Etnobotânica nos documentos. Dado este que reforça a premissa de que determinados conteúdos referentes ao ensino de Ciências da Natureza nos documentos RCG e BNCC, neste caso a Etnobotânica, apresentam lacunas, mostrando um ensino que ainda pode estar distante do saber popular (RAZERA, 2016) e das vivências dos alunos.

Superar o modelo tradicional de ensino e de aprendizagem não tem sido tarefa fácil para os professores, por não ter uma fórmula pronta. Para auxiliar, existem métodos de ensino que podem ser vistos e aplicados conforme a realidade vivenciada e as experiências dos alunos (MORÁN, 2015). Algumas metodologias, como experimentação, atividade investigativa, ou resolução de problemas, facilitam o aluno na construção do conhecimento e no processo de aprendizagem de forma ativa, tornando o aluno como personagem principal da sua aprendizagem (MÖRSCHBÄCHER, 2018).

Para que o aluno seja protagonista do seu conhecimento é necessário incentivar o pensamento crítico e o desenvolvimento de competências que permitem pôr em prática suas vivências, relacionando o conhecimento aprendido em sala de aula com o mundo real (PINTO et al., 2012). Person e Rocha (2020) relatam também que "um dos grandes desafios do ensino é desenvolver nos alunos a capacidade de refletir/pensar criticamente, dando sentido aos conhecimentos que estão sendo abordados e criando possibilidades de aprendizagem". 
Dentre tantas áreas que abrangem as Ciências da Natureza, o ensino da Botânica é um ramo de grande importância, muitas vezes dita de difícil compreensão ou difícil acesso, porém necessários para a construção de conhecimentos científico-biológicos e na formação de sujeitos críticos (DUTRA; GÜLLICH, 2016).

A utilização de metodologias de ensino diversificadas pode auxiliar na relação dos conhecimentos prévios com os conhecimentos científicos, através do resgate do que os alunos sabem sobre as plantas que fazem parte do seu cotidiano, bem como da sua utilização (DO NASCIMENTO et al, 2020). Os conhecimentos científicos são construídos a partir do saber e da prática que os alunos vivenciam na sociedade (MOREIRA; CANDAU, 2007).

Resgatando o conhecimento sobre as plantas, os alunos vão ter a sensação de pertencimento e entender a importância de estudar os vegetais, sentindo-se atraídos pelos conteúdos e tornando-se mais participativos nas aulas (DO NASCIMENTO et al, 2020).

Com a continuidade da análise, no quadro 4, encontrou-se a utilização de palavras correlacionadas a Etnobotânica nas habilidades descritas nos documentos, identificadas como: plantas, cobertura vegetal, ervas medicinais, célula vegetal, flora, floresta e recurso vegetal. Cada palavra foi observada no trecho de aparição, tendo como foco as habilidades dos documentos e o ano/série em que se aplica. Encontrou-se habilidades aplicadas em todos os anos finais do ensino fundamental $\left(5^{\circ}\right.$ ano a $9^{\circ}$ ano $)$ dos documentos que norteiam a abordagem do assunto em sala de aula.

Isso demonstra que os documentos estudados possuem abordagens que podem possibilitar o conhecimento e a aprendizagem do ensino de Botânica, trazendo consigo o ensino da Etnobotânica, de modo indireto e pouco expressivo, possibilitando a aplicação em propostas pedagógicas nos anos finais do ensino fundamental, e a aproximação, ainda que tímida, entre o saber científico e popular.

Quadro 4 - Utilização de palavras correlacionadas a Etnobotânica (quais/quantas/qual contexto).

\begin{tabular}{|c|c|c|c|}
\hline Qual palavra? & $\begin{array}{c}\text { Trecho (frase ou } \\
\text { parágrafo) }\end{array}$ & Contexto & Documento/Página \\
\hline
\end{tabular}




\begin{tabular}{|c|c|c|c|}
\hline $\begin{array}{l}\text { Cobertura } \\
\text { Vegetal }\end{array}$ & $\begin{array}{c}\text { (EF05CI03) Selecionar } \\
\text { argumentos que justifiquem } \\
\text { a importância da cobertura } \\
\text { vegetal para a manutenção } \\
\text { do ciclo da água, a } \\
\text { conservação dos solos, dos } \\
\text { cursos de água e da } \\
\text { qualidade do ar atmosférico. }\end{array}$ & $\begin{array}{l}\quad 5^{\circ} \text { ano } \\
\text { Habilidade BNCC } \\
\text { Matéria e Energia }\end{array}$ & $\begin{array}{c}\text { RCG (página 72) } \\
\text { BNCC (página 341) }\end{array}$ \\
\hline $\begin{array}{l}\text { Cobertura } \\
\text { Vegetal }\end{array}$ & $\begin{array}{c}\text { (EF05CI03RS-2) Comparar } \\
\text { os ambientes que apresentam } \\
\text { cobertura vegetal, a } \\
\text { desertificação e os que } \\
\text { sofreram intervenção } \\
\text { humana. }\end{array}$ & $\begin{array}{l}\qquad 5^{\circ} \text { ano } \\
\text { Habilidade RCG } \\
\text { Matéria e Energia }\end{array}$ & RCG (página 72) \\
\hline Ervas Medicinais & $\begin{array}{c}\text { (EF06CI04RS-4) } \\
\text { Compreender os malefícios } \\
\text { da automedicação, } \\
\text { tradicional ou por ervas } \\
\text { medicinais, entendendo a } \\
\text { importância da orientação } \\
\text { médica para qualquer tipo de } \\
\text { medicamento. }\end{array}$ & $\begin{array}{c}\quad 6^{\circ} \text { ano } \\
\text { Habilidades RCG } \\
\text { Matéria e energia }\end{array}$ & RCG (página 79) \\
\hline Célula Vegetal & $\begin{array}{c}\text { (EF06CI05RS-4) Diferenciar } \\
\text { a célula animal da célula } \\
\text { vegetal para o estudo da } \\
\text { fotossíntese. }\end{array}$ & $\begin{array}{l}\quad 6^{\circ} \text { ano } \\
\text { Habilidade RCG } \\
\text { Vida e Saúde }\end{array}$ & RCG (página 80) \\
\hline V / Flora & $\begin{array}{l}\text { (EF07CI07) Caracterizar os } \\
\text { principais ecossistemas } \\
\text { brasileiros quanto à } \\
\text { paisagem, à quantidade de } \\
\text { água, ao tipo de solo, à } \\
\text { disponibilidade de luz solar, } \\
\text { à temperatura etc., } \\
\text { correlacionando essas } \\
\text { características à flora e fauna } \\
\text { específicas. }\end{array}$ & $\begin{array}{l}7^{\circ} \text { ano } \\
\text { Habilidade BNCC } \\
\text { Vida e Saúde }\end{array}$ & $\begin{array}{c}\text { RCG (página 89) } \\
\text { BNCC (página 347) }\end{array}$ \\
\hline Flora & $\begin{array}{c}\text { (EF07CI07RS-2) Identificar } \\
\text { os ecossistemas locais } \\
\text { investigando a flora e a } \\
\text { fauna da mesma. }\end{array}$ & $\begin{array}{l}7^{\circ} \text { ano } \\
\text { Habilidade RCG } \\
\text { Vida e Saúde }\end{array}$ & RCG (página 89) \\
\hline Plantas & $\begin{array}{l}\text { (EF08CI07) Comparar } \\
\text { diferentes processos } \\
\text { reprodutivos em plantas e } \\
\text { animais em relação aos }\end{array}$ & $\begin{array}{l}\qquad 8^{\circ} \text { ano } \\
\text { Habilidade BNCC }\end{array}$ & $\begin{array}{c}\text { RCG (página 98) } \\
\text { BNCC (página 349) }\end{array}$ \\
\hline
\end{tabular}




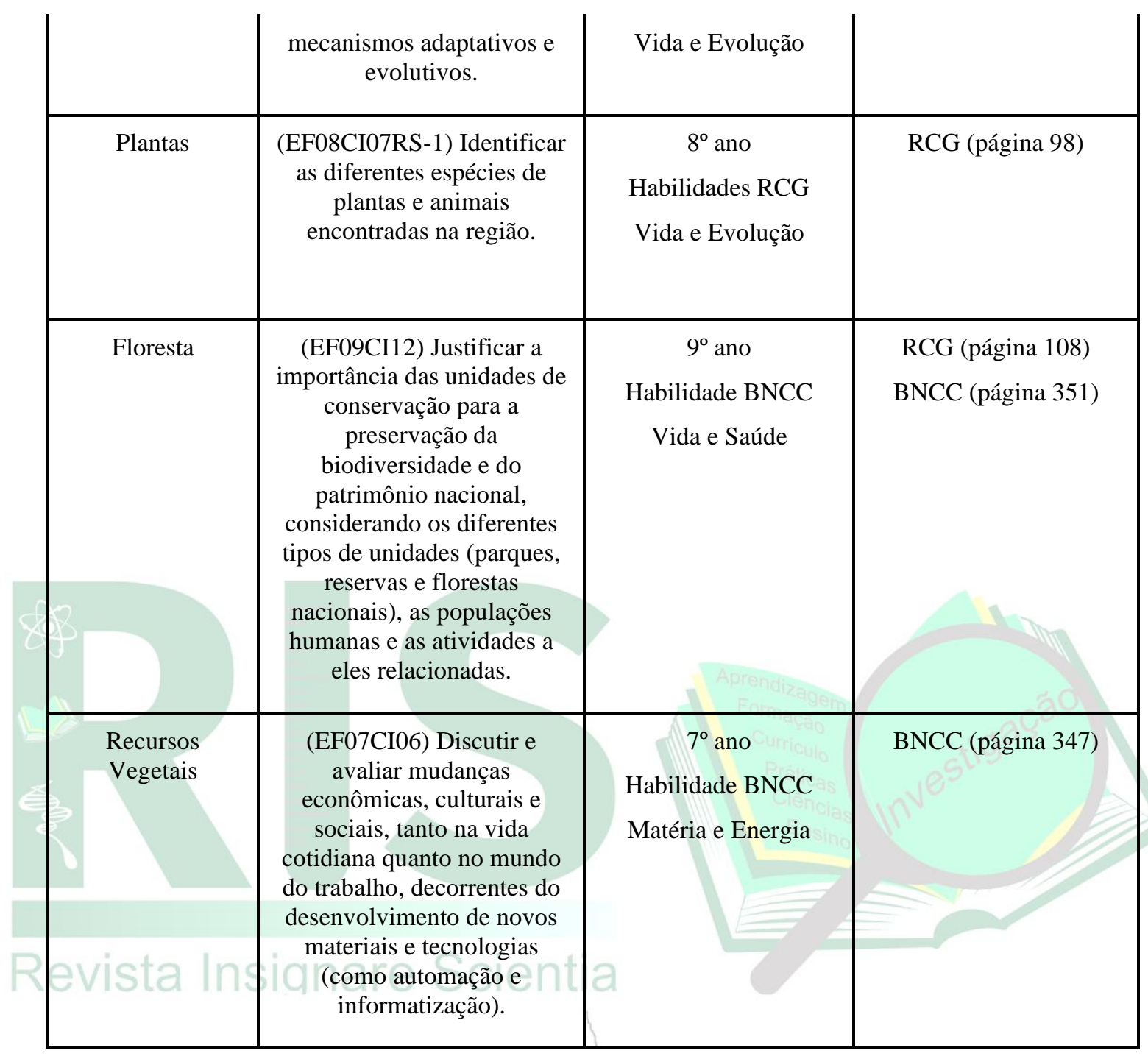

Fonte: Adaptado de Soruco et al. (2019); Leite et al. (2019).

Na sugestão de estratégias pedagógicas, no quadro 5, observou-se as metodologias para alcançar o conhecimento científico em Etnobotânica, identificadas pelas habilidades que auxiliam o professor na mediação do conhecimento de uma forma geral, valorizando o conhecimento popular dos alunos. Os dados foram encontrados somente no documento gaúcho (RCG), com um número menor que o esperado por se tratar de um documento específico do Rio Grande do Sul, um estado reconhecido para valorização e culto às tradições gaúchas. Na BNCC, documento direcionado a educação nacional aplicada em 
qualquer região do Brasil, não se identificou nenhuma metodologia referente ou que se aproximasse ao tema Etnobotânica.

O RCG apresenta poucas estratégias pedagógicas que auxiliam o professor a difundir o conhecimento sobre Etnobotânica em sala de aula, porém possibilita o conhecimento popular dos alunos facilitando o caminho da aprendizagem sobre o tema abordado, trazendo o conhecimento científico como forma de complementar o ensino.

Quadro 5 - Perspectivas de estratégias metodológicas relacionadas a Etnobotânica no documento (Sugere o que? Para trabalhar o que e/ou quando e para quem?).

\begin{tabular}{|c|c|c|c|}
\hline $\begin{array}{c}\text { Sugestão de } \\
\text { estratégias/metodologia } \\
\text { s para alcançar o } \\
\text { conhecimento científico } \\
\text { em Etnobotânica? } \\
\text { Página? }\end{array}$ & $\begin{array}{c}\text { Descrição da } \\
\text { sugestão/trecho do } \\
\text { texto }\end{array}$ & $\begin{array}{c}\text { Voltado a que } \\
\text { público? } \\
\text { (Professor/aluno/esc } \\
\text { ola) }\end{array}$ & Documento/ Página \\
\hline $\begin{array}{c}\text { (EF06CI04RS-2) } \\
\text { Diferenciar quais } \\
\text { medicamentos são } \\
\text { naturais e quais são } \\
\text { sintéticos. }\end{array}$ & $\begin{array}{c}\text { Identificar os diferentes } \\
\text { medicamentos. }\end{array}$ & Professor $\rightarrow$ Aluno & RCG (página 79) \\
\hline $\begin{array}{c}\text { (EF06CI04RS-4) } \\
\text { Compreender os } \\
\text { malefícios da } \\
\text { tradicional ou por ervas } \\
\text { tradicionalicac̃o, O } \\
\text { medicinais, entendendo a } \\
\text { importância da } \\
\text { orientação médica para } \\
\text { qualquer tipo de } \\
\text { medicamento. }\end{array}$ & $\begin{array}{c}\text { Conhecer os malefícios } \\
\text { da automedicação, } \\
\text { tradicional ou por ervas } \\
\text { ar medicinais e a } \\
\text { importância da } \\
\text { orientação médica para } \\
\text { uso de medicamentos }\end{array}$ & $\begin{array}{l}\text { Professor } \rightarrow \text { Aluno } \\
\text { Aluno } \rightarrow \text { Professor }\end{array}$ & RCG (página 79) \\
\hline $\begin{array}{c}\text { (EF06CI04RS-5) } \\
\text { Associar a biodiversidade } \\
\text { brasileira à } \\
\text { potencialidade de } \\
\text { desenvolvimento de } \\
\text { novos medicamentos, } \\
\text { relacionando a } \\
\text { importância da } \\
\text { preservação da } \\
\text { biodiversidade para a } \\
\text { cura de doenças. }\end{array}$ & $\begin{array}{l}\text { Valorizar e conhecer a } \\
\text { biodiversidade } \\
\text { brasileira com âmbito } \\
\text { de desenvolver novos } \\
\text { medicamentos e a } \\
\text { importância de } \\
\text { preservar a } \\
\text { biodiversidade para a } \\
\text { cura de doenças. }\end{array}$ & Professor $\rightarrow$ Aluno & RCG (página 79) \\
\hline
\end{tabular}

Fonte: Adaptado de Soruco et al. (2019); Leite et al. (2019). 
Com isso, os dados encontrados nos mostram, de maneira singela, uma relação com os estudos da área de Botânica, destacando a importância da Etnobotânica no ensino de Ciências da Natureza. A Etnobotânica como um ramo de ensino botânico, de grande relevância e potencial para possibilitar o reconhecimento do saber popular através do conhecimento científico.

Apesar do ensino de Etnobotânica se caracterizar como uma área do conhecimento relativamente nova, apresenta uma aproximação com o compromisso social da pesquisa científica, a partir do estabelecimento de diálogos contundentes e concatenados entre diversas áreas, como as Ciências Biológicas e Humanas, inclusive a Educação (COSTA; PEREIRA, 2016). Segundo Siqueira (2011) o ensino de Etnobotânica auxilia na valorização dos conhecimentos que os alunos trazem para a escola, permitindo que a aprendizagem se torne significativa, a partir da relação dos conhecimentos científicos com o cotidiano.

Para isso, compreender a aproximação do aluno com o conhecimento científico, apropriando-se dos seus conhecimentos populares pode não ocorre com o uso de uma metodologia simples ou estruturada a qual o aluno é orientado como deve seguir para aprendes (PERSON; ROCHA, 2020). E sim, deve despertar um sentimento de motivação, de curiosidade e investigação no aluno, de forma que o aluno seja protagonista do ensino e aprendizagem.

O resgate dos saberes trazidos pelos alunos, contribui para o ensino de Ciências da Natureza por meio de estratégias e metodologias que buscam interligar os conhecimentos científicos e populares, resgatando o conhecimento tradicional e local (KOVALSKI; OBARA, 2013).

Essa interligação entre o saber popular e o ensino de Ciências auxilia os estudantes a expressarem suas crenças e seus conhecimentos prévios sobre os assuntos tratados, dando suporte à aprendizagem do novo tema da Botânica a ser abordado (URSI et al., 2018). 


\section{CONCLUSÃO}

Este estudo buscou reconhecer os documentos oficiais - Referencial Curricular Gaúcho e Base Nacional Comum Curricular - como políticas públicas que orientam a educação básica gaúcha e brasileira, quanto à aproximação entre a Etnobotânica e a educação científica. Nesta análise, identificou-se nos documentos o tema Etnobotânica no âmbito das Ciências da Natureza quanto à sua descrição e perspectivas pedagógicas reconhecendo as expressões, as estratégias metodológicas e o público-alvo com suas abordagens referentes ao tema.

Com a análise documental encontrou-se informações relacionadas à Etnobotânica, um tema que ainda carece de estudos, pouco abordado pelo professor em sala de aula e que não é suficientemente reconhecido pela comunidade escolar, apesar das suas significativas relações sociais e culturais engajadas ao conhecimento científico.

A partir dos resultados, é possível perceber a necessidade e a importância de refletir sobre o tema em sala de aula oportunizando o aluno a expressar seus saberes, estimulando a educação científica e aprimorando seus conhecimentos. Bem como, motivar os professores de Ciências da Natureza, através de formações que abordar assuntos relacionados a Botânica, com diversas práticas pedagógicas que promovam o ensino e aprendizagem.

Como perspectivas futuras destacam-se os estudos de outros documentos pertinentes à educação básica; a verificação do material pedagógico, em especial o livro didático; e a proposição de estratégias para o ensino e a aprendizagem do tema.

\section{REFERÊNCIAS}

ALBUQUERQUE, U. P. Introdução à etnobotânica. 2 ed. Rio de Janeiro: Editora Interciência, 2005.

ALBUQUERQUE, U. P.; LUCENA, R. F. P.; CUNHA, L. V. F. C. Métodos e técnicas na pesquisa etnobiológica e etnoecológica. Recife: NUPEEA, 2010.

ARAÚJO, T. A. S.; ALBUQUERQUE, U. P. Encontros e desencontros na pesquisa etnobiológica e etnoecológica: os desafios do trabalho em campo. Recife: Nupeea, 2009. 
BARDIN, L. Análise de conteúdo. 70º ed. São Paulo. 2011 [1977].

BATISTA, L. N.; ARAÚJO, J. N. A botânica sob o olhar dos alunos do ensino médio. Revista Amazônica de Ensino de Ciências - Areté. Manaus, AM. v. 8, n. 15, p. 109$120,2015$.

BICA, A. C. A Organização da Educação Pública Municipal no Governo de Carlos Cavalcanti Mangabeira (1925-1929) no município de Bagé/RS. Orientadora: $\operatorname{Prof}^{\mathrm{a}}{ }^{\mathrm{D}} \mathrm{Dr}^{\mathrm{a}}$ Berenice Corsetti. 2013. 301 f. Tese (Doutorado em Educação) - Universidade do Vale do Rio dos Sinos. São Leopoldo, RS. 2013.

BRASIL. Base Nacional Comum Curricular. 2018a. Disponivel em: http://basenacionalcomum.mec.gov.br/images/BNCC_EI_EF_110518_versaofinal_site. pdf. Acessado em: 30 jan. 2020.

BRASIL. Ciências da natureza, matemática e suas tecnologias. Secretaria de Educação Básica. Orientações curriculares para o ensino médio. - Brasília: Ministério da Educação, Secretaria de Educação Básica. v. 2, p. 135, 2006b. Disponível em: http://portal.mec.gov.br/seb/arquivos/pdf/book_volume_02_internet.pdf. Acessado em: 25 jun. 2019.

BRASIL. Secretaria de Estado da Educação. Referencial Curricular Gaúcho: Ciências da Natureza. Departamento Pedagógico. Porto Alegre. v.1, 2018c. Disponível em: http://portal.educacao.rs.gov.br/Portals/1/Files/1530.pdf. Acesso em: 25 ago. 2019.

BRIÃO, D.; ARTICO, L. L.; LÍMA, L. F. P.; MENEZES, A. P. S. Utilização de plantas medicinais em um município inserido no bioma pampa brasileiro. Revista da Universidade Vale do Rio Verde. Três Corações, MG. v. 14, n. 2, p. 206-219, 2016.

CHASSOT, A. Alfabetização científica: questões e desafios para a educação. Ijuí, RS. Editora Ijuí, 2011a.

CHASSOT, A. Fazendo Educação em Ciências em um Curso de Pedagogia com Inclusão de Saberes Populares no Currículo. Revista Química Nova na Escola, São Paulo, SP. n. 27, p. 9-12, fev. 2008 b.

COUTINHO, C. Por uma "Ciência com Consciência": Interfaces da Educação Ambiental e do Ensino de Ciências nos Contextos Docentes, Discentes e do Material Didático. Orientadora: Prof ${ }^{\mathrm{a}}$. Dr ${ }^{\mathrm{a}}$. Martha Bohrer Adaime. Tese (Doutorado em Educação em Ciências) - Universidade Federal de Santa Maria (UFSM), Santa Maria, RS. 2017.

Recebido em: $31 / 03 / 2020$

Aceito em: $23 / 12 / 2020$ 
COSTA, S.; PEREIRA, C. Etnobotânica como subsídio para a educação ambiental nas aulas de ciências. Revista Brasileira de Educação - Revbea. São Paulo, SP. v.11, n. 2, p. 279-298, 2016.

DELIZOICOV, D.; ANGOTTI, J. A.; PERNAMBUCO, M. M. Ensino de Ciências: fundamentos e métodos. 4 ed. São Paulo, SP: Editora Cortez, 2011.

DIAS, D. B. R.; GRECO, A. F.; SGANZERLA, F. L.; MARZARI, M. R. B. Letramento Científico: perspectivas presentes no Referencial Curricular Gaúcho. III SIMPÓSIO INTEGRADO DOS PPGs UNIPAMPA/Campus Uruguaiana, 2019, Uruguaiana. Anais [...]. Uruguaiana, RS. 2019.

DO NASCIMENTO, A. S.; CARDOSO, J. V. M.; SANTOS, F. W. R.; DE ABREU MACÊDO, J. R. Ensino de Biologia: resgate cultural do etnoconhecimento associado ao uso de plantas medicinais/Biology teaching: cultural rescue of ethno-knowledge associated with the use of medicinal plants. Brazilian Journal of Development, v. 6, n. 5, p. 31084-31096, 2020.

DUTRA, A. P.; GÜLLICH, R. I. C. Ensino de Botânica: metodologias, concepções de ensino e currículo. Revista em Ensino de Ciências e Tecnologia, Santo Ângelo, RS. v. 6, n. 2. jul./dez. 2016.

FERREIRA, G.; CAMPOS, M. G. P. A.; PEREIRA, B. L.; SANTOS, G. B. A Etnobotânica e o Ensino de Botânica do Ensino Fundamental: possibilidades metodológicas para uma prática contextualizada. Boletin do Grupo de Pesquisa da Flora, Vegetação e Etnobotânica - FLOVET, Cuiabá, MG. v.1, n.9, 2017.

FERREIRA, V. E. M. Um estudo sobre a utilização das plantas medicinais na rede de ensino de Dom Pedrito-RS e perspectivas pedagógicas. Orientadora: Profa. Dra. Crisna Daniela Krause Bierhalz Monografia (Trabalho de Conclusão de Curso - TCC) Universidade Federal Do Pampa - UNIPAMPA Campus Dom Pedrito. Dom Pedrito, RS. 2018.

FONSECA-KRUEL, V. S.; PEIXOTO, A. L. Etnobotânica na Reserva Extrativista Marinha de Arraial do Cabo. Rio de Janeiro, RJ. Acta Botânica Brasilica, v.18, n.1, p. 177-190, 2004.

GIRALDI, M.; HANAZAKI, N. Uso e conhecimento tradicional de plantas medicinais no Sertão do Ribeirão, Florianópolis, SC, Brasil. Acta botanica brasilica, v. 24, n. 2, p. 395-406, 2010.

GUARIM, V. L. M. S. Educação e sustentabilidade ambiental em comunidades ribeirinhas tradicionais. Cuiabá: IE/UFMT, 2000. 
HAMILTON, A. C.; SHENGJI, J. P.; KESSY, J.; KHAN, A. A.; LAGOS-WITTE, S.; SHINWARIi, Z. K. The purposes and teaching of applied ethnobotany. United Nations Educational, Scientific and Cultural Organization (UNESCO), 2003.

KINOSHITA, L. S.; TORRES, R. B.; TAMASHIRO, J. Y.; FORNI-MARTINS, E. R. A Botânica no Ensino Básico: relatos de uma experiência transformadora. Editora Livraria RiMa. São Carlos, SP. 2006.

KOVALSKI, M. L.; OBARA, A. T. O estudo da etnobotânico das plantas medicinais na escola. Revista Ciências e Educação. Bauru, SP. v. 19, n. 4, p. 911-927, 2013.

KRUEL, V. S. F.; SILVA, I. M.; PINHEIRO, L. U. B. O Ensino Acadêmico da Etnobotânica no Brasil. Revista do Jardim Botânico do Rio de Janeiro - Rodriguésia. Rio de Janeiro, RJ. v.56, n.87, p.97-106, 2005.

LEITE, A. P.; CARVALHO, I.; GONÇALVES, F. T.; RUPPENTHAL, R. Estratégias para desenvolver o letramento científico: uma análise do Referencial Curricular Gaúcho. III SIMPÓSIO INTEGRADO DOS PPGs UNIPAMPA/Campus Uruguaiana. Anais [...]. Uruguaiana, RS, 2019.

LIMA, T. N. M.; OLIVEIRA, D. M.; GOMES, L. J.; MELLO, A. A.; FERREIRA, R. A. Etnobotânica e estrutura populacional da Mangabeira (Hancornia speciosa Gomes) em assentamento agroextrativista. Pirambu, SE. Ethnoscientia. v. 4, 2019. Ethnoscientia 4, 2019. Disponível em: file:///C:/Users/User/Downloads/207-962-1PB.pdf. Acesso em: 25 nov. 2019.

MOREIRA, A. F. B.; CANDAU, V. M. Currículo, conhecimento e cultura. Indagações sobre currículo: currículo, conhecimento e cultura. Brasília: Ministério da Educação, Secretaria de Educação Básica, p. 17-44, 2007.

MÖRSCHB ÄCHER, J. L. Contribuições e desafios da metodologia instrução entre pares: um estudo de caso no ensino técnico. 2018.

PERSON, V. A.; DA ROCHA, J. B. T. Inter-relação entre metodologias didáticas, motivos e aprendizagem em Bioquímica. Revista Insignare Scientia-RIS, v. 3, n. 2, p. 101-118, 2020.

RAZERA, J. C. C. Contribuições da Cienciometria para a área brasileira de Educação em Ciências. Revista Ciências e Educação. Bauru, SP. v. 22, n. 3, p. 557-560, 2016. Disponível em: http://www.scielo.br/pdf/ciedu/v22n3/1516-7313-ciedu-22-03-0557.pdf. Acessado em 27 jan 2020.

ROCHA, J. A.; BOSCOLO, O. H.; FERNANDES, L. R. R. M. V. Etnobotânica: um instrumento para valorização e identificação de potenciais de proteção do conhecimento tradicional. Interações. Campo Grande, MS. v. 16, n. 1, p. 67-74, 2015. 
RUPPENTHAL, R. O ensino do sistema respiratório através da contextualização e de atividade práticas. Orientadora: Prof ${ }^{\mathrm{a}}$. Dr ${ }^{\mathrm{a}}$. Maria Rosa Chitolina Schetinger. Dissertação (Mestrado em Educação em Ciências: Química da Vida e Saúde). Universidade Federal de Santa Maria - UFSM. Santa Maria, RS. 2013.

SASSERON, L. H.; CARVAlHO, A. M. P. Alfabetização Científica: uma revisão bibliográfica. Investigações em Ensino de Ciências. Porto Alegre, RS. v.16, n.1, p. 5977, 2011.

SASSERON, L. H.; DUSCHL, R. A. Ensino de Ciências e as Práticas Epistemológicas: o papel do professor e o engajamento dos estudantes. Investigações em Ensino de Ciências. Porto Alegre, RS v.21, n. 2, p. 52-67, 2016.

SILVA, J. A.; RAMOS, M. A. Contribuições da etnobiologia para formação continuada de professores de ciências da educação escolar quilombola. Revista Electrónica de Enseñanza de las Ciencias. v. 19, n. 1, p. 132-158, 2019. Disponível em: http://reec.uvigo.es/volumenes/volumen19/REEC_19_1_7_ex1551.pdf. Acessado em: 23 de jan. 2020.

SIQUEIRA, A. B. Etnobotânica no currículo de ciências na educação de jovens e adultos. REMEA-Revista Eletrônica do Mestrado em Educação Ambiental, v. 26, 2011.

SORUCO, T. M. O.; LIMA, Q. C. E.; RODRIGUES, J. M.; CANTO-DOROW, T. S.; COUTINHO, C. Os níveis do Letramento Científico no Referencial Curricular Gaúcho: um olhar para as habilidades descritas no documento. III SIMPÓSIO INTEGRADO DOS PPGs UNIPAMPA/Campus Uruguaiana. Anais [...]. Uruguaiana/RS, 2019.

URSI, S.; BARBOSA, P. P.; SANO, P. T.; BERCHEZ, F. A. S. Ensino de Botânica: conhecimento e encantamento na educação científica. Revista Estudos Avançados. São Paulo, SP. v. 32, n. 94, set/dez, 2018. Disponível em: http://www.scielo.br/pdf/ea/v32n94/0103-4014-ea-32-94-00007.pdf. Acessado em: 21 jan 2020.

Recebido em: $31 / 03 / 2020$

Aceito em: 23/12/2020 